\title{
Orally Administered D-Aspartate Depresses Rectal Temperature and Alters Plasma Triacylglycerol and Glucose Concentrations in Broiler Chicks
}

\author{
Edi Erwan ${ }^{1}$, Zulfikar $^{1}$, Eniza Saleh ${ }^{1}$, Bambang Kuntoro ${ }^{1}$, Vishwajit Sur Chowdhury ${ }^{2}$ and Mitsuhiro Furuse ${ }^{3}$ \\ ${ }^{1}$ Department of Animal Science, Faculty of Agriculture and Animal Science, \\ State Islamic University of Sultan Syarif Kasim Riau, Indonesia \\ ${ }^{2}$ Division for Experimental Natural Science, Faculty of Arts and Science, Graduate School of \\ Bioresource and Bioenvironmental Sciences, Kyushu University, Fukuoka 819-0395, Japan \\ ${ }^{3}$ Laboratory of Regulation in Metabolism and Behavior, Graduate School of Bioresource and Bioenvironmental Sciences, \\ Kyushu University, Fukuoka 812-8581, Japan
}

\begin{abstract}
L-Aspartate (L-Asp), D-aspartate (D-Asp) or their chemical conjugates plays important physiological roles in regulating food intake, plasma metabolites and thermoregulation in animals. However, there are very few studies available in layers and no reports have been found in broilers. Broilers are very important commercial birds for meat production, so effects of L- or D-Asp in broilers would provide new physiological insight of this strain. Therefore, the purpose of this study was to determine the effect of oral administration of L- or D-Asp on feed intake, rectal temperature and some plasma metabolites in broiler chicks. Broiler chicks (5 days old) were orally administered with different doses $(0,3.75,7.5$ and $15 \mathrm{mmol} / \mathrm{kg}$ body weight) of L- or D-Asp. At $120 \mathrm{~min}$ after administration of L- or D-Asp, the blood was immediately collected through the jugular vein. The rectal temperature of chicks was measured at 30,60 and $120 \mathrm{~min}$ after administration using a digital thermometer with an accuracy of $\pm 0.1^{\circ} \mathrm{C}$, by inserting the thermistor probe in the rectum to a depth of $2 \mathrm{~cm}$. A repeated-measures two-way ANOVA was applied for the analysis of feed intake and rectal temperature. Plasma metabolites were statistically analyzed by one-way ANOVA and regression equations. The study showed that oral administration of both L- and D-Asp did not alter feed intake. However, D-Asp, but not L-Asp, dose-dependently decreased the rectal temperature in chicks. It was also found that DAsp increased plasma glucose and decreased triacylglycerol concentrations. The changes in plasma metabolites further indicate that D-Asp treatment modulates the energy metabolism in broiler chicks. In conclusion, D-Asp may be a beneficial nutrient not only for layers but also for broilers, since orally administered D-Asp lowered rectal temperature without reducing feed intake.
\end{abstract}

Key words: broiler chicks, D-aspartate, L-Aspartate, plasma metabolites, rectal temperature

J. Poult. Sci., 54: 205-211, 2017

\section{Introduction}

High ambient temperature (HT) induced-heat-stress is a serious concern over the globe. The Intergovernmental Panel on Climate Change (IPCC) (2015) reported that the global surface temperature is increasing in this century. Therefore, probably summer time is becoming more unbearable in many tropical and subtropical countries. It is well known that summer heat stress is causing a great economic loss in commercial poultry sector. Donkoh (1989) reported

Received: February 4, 2016, Accepted: December 21, 2016

Released Online Advance Publication: January 25, 2017

Correspondence: Edi Erwan, Ph.D., Laboratory of Technology in Animal Production Department of Animal Science, Faculty of Agriculture and Animal Science State Islamic University of Sultan Syarif Kasim Riau, Pekanbaru, Riau, Indonesia. (E-mail: erwan_edi@yahoo.com) that continuous exposure of broilers to HT markedly affected their performance and physiological functions. In addition, HT induces quick increment of deep body temperature even in chicks (Chowdhury et al., 2012) and causes oxidative stress (Chowdhury et al., 2014). To cool down the temperature in the poultry house using fossil energy leads further increase in the environmental temperature. Therefore, it is very important to find out other strategies to control the body temperature in the chicken. For instance, suitable nutrients or drugs to reduce high body temperature when exposed to HT should be clarified. Nutrients, especially amino acids, are widely applied as anti-stress agents with regard to psychological and physiological stress (Yamane et al., 2009; Hamasu et al., 2010; Erwan et al., 2012, 2014b). Amino acid in particular essential amino acids supplementation has been performed in order to overcome heat-stress problems in 
birds (Mendes et al., 1997; Brake et al., 1998; Willemsen et al., 2011; Dai et al., 2012). However, not only essential amino acids, but also non-essential amino acids may be useful to mitigate heat-stress problems. Recently, Chowdhury et al. (2015) showed that a non-essential amino acid, Lcitrulline, reduced body temperature in young chicks and suggested its possibility to use as a hypothermic agent under heat-stress in chickens.

Amino acids can exist in two-mirror-image form (L- or Dform) termed enantiomers. Aspartate (Asp), which is a nonessential amino acid, plays important roles as a constituent of protein synthesis, a precursor of specific neurotransmitters and physiological modulators (Spinelli et al., 2006; Schell et al., 1997; Errico et al., 2009). L- and D-Asp have been shown to occur in various brain regions of chickens (Neidle and Dunlop, 1990) and pigeons (Kera et al., 1996). As far as the physiological roles in correlation with D-Asp in mammals and birds are concerned, important biological functions of this amino acid are now postulated (Topo et al., 2010). Though some evidence to date suggests that D-Asp plays important physiological roles in adult organisms, little is known about the function of D-Asp during an early development when its level is physiologically high (Homma, 2007; Errico et al., 2008).

It has been reported that the injection of D-Asp released the antidiuretic hormone arginine vasopressin (AVP) in rats (Koyuncuoğlu et al., 1984). Studies in rats have further shown that D-Asp not only lowered body temperature after oral administration (Koyuncuoğlu et al., 1982a; Koyuncuoğlu and Berkman, 1982), but also decreased plasma triacylglycerol (TG) (Koyuncuoğlu et al., 1982b). We have previously shown that intracerebroventicular (i.c.v.) injection of either L- or D-Asp clearly attenuated stress responses in layer chicks (Yamane et al., 2009; Erwan et al., 2012, 2014b) and oral administration of D-Asp decreased feed intake, body temperature and altered some plasma metabolites in layer chicks (Erwan et al., 2013a, 2014a). Hence, L- or D-Asp may act as a modulator of important physiological functions in chicks. However, some physiological functions are different between layer and broiler chicks. Tachibana et al. (2001) reported that agouti-related peptide, a potent stimulator of feed intake (Rossi et al., 1998), stimulated feed intake only in layer type chicks but not broiler chicks. Therefore, it is important to know whether D-Asp can regulate body temperature and influence feed intake in broilers. The purpose of this study was to evaluate the effect of L- or D-Asp on feed intake, body temperature and plasma metabolites in broiler chicks.

\section{Materials and Methods}

\section{Animals and Drugs}

One-day-old broiler chicks (Cobb) (Gallus gallus domesticus) were purchased from a local hatchery (Charoen Pokphand Jaya Farm Ltd, Pekanbaru, Indonesia) and housed in a wooden cage $(50 \times 35 \times 33 \mathrm{~cm})$ in a group $(25 \mathrm{birds})$ at a constant temperature of $30 \pm 1{ }^{\circ} \mathrm{C}$ with continuous lighting. Feed (metabolizable energy: $>3,050 \mathrm{kcal} / \mathrm{kg}$, protein: $>$
23.5\%: commercial starter diet, 311-VIVO, Pokphand Tbk, Medan, Indonesia) and water were provided ad libitum. One day before the experiment (4 days old), thirty two chicks (Means \pm S.E.M. were $92.1 \pm 2.0 \mathrm{~g}$ in Experiment 1 and 92.8 $\pm 1.7 \mathrm{~g}$ in Experiment 2) were reared individually in cages $(20 \times 25 \times 25 \mathrm{~cm})$ and assigned for treatment and control groups on the basis of their body weight in order to produce uniform groups in both Experiments 1 and 2. This study was performed in accordance with the guidelines for animal experiments carried out at the Faculty of Agriculture and Animal Science, State Islamic University of Sultan Syarif Kasim Riau, Pekanbaru, Indonesia.

Both of L- and D-Asp were purchased from Wako Pure Chemical Industries (Osaka, Japan).

\section{Administration of $L$ - or $D$-Asp}

Following an acclimatization period with individual rearing for $24 \mathrm{hr}$, chicks were randomly selected and divided into four groups, each group consisting of 8 chicks. The birds were provided with ad libitum access to the diet during the whole experimental period. On the day of the experiment, each chick (5 days old) was orally administered either a solution of L-Asp (Experiment 1) or D-Asp (Experiment 2) for the treatment groups, or distilled water (DW) for the control group, via an elastic plastic needle on a small syringe. Based on our recent report on L- or D-Asp in layer chicks (Erwan et al., 2013a, 2014a), oral administration of L- or DAsp in Experiments 1 and 2, has been designed to use 3.75, 7.5 and $15.0 \mathrm{mmol} / \mathrm{kg}$ body weight as the low, medium and high doses, respectively.

\section{Measurement of Feed Intake and Rectal Temperature}

Feed intake (at 30,60 and $120 \mathrm{~min}$ ) was determined by measuring the reduction in the amount of feed consumed from a pre-weighed feeder. The rectal temperature of chicks was also measured at 30-, 60- and 120-min of the experimental time with a digital thermometer with an accuracy of $\pm 0.1^{\circ} \mathrm{C}$ (Thermalert TH-5, Physitemp Instruments Inc., USA) by inserting the thermistor probe into the rectum through cloaca to a depth of $2 \mathrm{~cm}$ from anus. It took about 5 $\mathrm{sec}$ to measure rectal temperature by inserting the probe.

\section{Blood Collection and Analysis of Plasma Metabolites}

At 120 min after administration of L- or D-Asp, all birds in each group ( $n=6-8$ per group) were sacrificed and their bloods were collected for analysis of plasma metabolites. Blood was collected through jugular vein into heparinized eppendorf tubes and centrifuged at $5,000 \times \mathrm{g}$ for $15 \mathrm{~min}$. Plasma was stored at $-20^{\circ} \mathrm{C}$ until assay. The plasma metabolites (TG, glucose, total cholesterol (TCHO) and total protein (TP)) were measured with Microlab 300 (Vital Scientific, Netherland) as per the manufacturer's instructions. All the samples were assayed together and in a random sequence for each metabolite.

\section{Statistical Analysis}

For the rectal temperature, a repeated-measures two-way analysis of variance (ANOVA) was applied. Plasma metabolites were statistically analyzed by one-way ANOVA and regression equations. The Tukey test was done as a post hoc test. Significant differences were denoted as $P<0.05$. 
Values were presented as means \pm S.E.M. Statistical analysis was carried out using the commercially available package StatView (Version 5, SAS Institute, Cary, USA, 1998). All data in each group were first subjected to a Thompson rejection test to eliminate outliers $(P<0.05)$, and the remaining data were used for the analysis among groups.

\section{Results}

Experiment 1: Effects of L-Asp on Feed Intake, Rectal Temperature and Plasma Metabolites

Oral administration of several doses of L-Asp did not significantly alter feed intake at $2 \mathrm{~h}$ in chicks (Means $(\mathrm{g}) \pm$ S.E.M. were $47.8 \pm 1.8$ in the control group, $47.5 \pm 2.8$ in the low L-Asp group, 47.9 \pm 1.3 in the medium L-Asp group, and $50.3 \pm 1.5$ in the high L-Asp group, respectively). As shown in Fig. 1, rectal temperatures of chicks were not changed significantly by the oral administration of L-Asp. Table 1 shows the effect of oral administration of several doses of L-Asp on the concentration of plasma metabolites. There was no significant effect of L-Asp on the concentration of plasma metabolites.

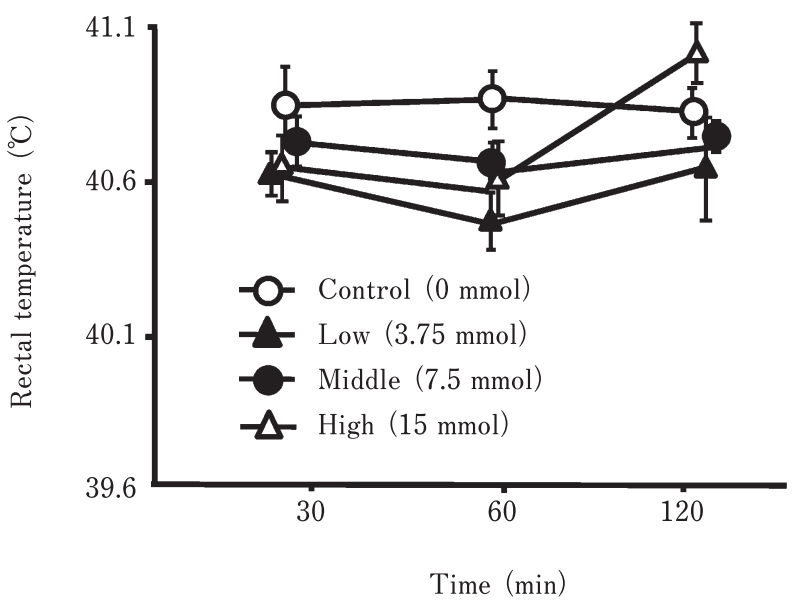

Fig. 1. Effect of orally L-Asp (3.75, 7.5 and $15.0 \mathrm{mmol} /$ kg) administration on rectal temperatures in chicks during $120 \mathrm{~min}$ of the experimental period (Experiment 1). The number of chicks used in each group ranged between 5-7. Values are means \pm S.E.M.

\section{Experiment 2: Effects of D-Asp on Feed Intake, Rectal Temperature and Plasma Metabolites}

Oral administration of several doses of D-Asp did not significantly alter feed intake in chicks (Means $(\mathrm{g}) \pm$ S.E.M. were $46.6 \pm 2.1$ in the control group, $46.7 \pm 2.8$ in the low LAsp group, 49.0 \pm 2.6 in the medium L-Asp group, and 47.9 \pm 2.0 in the high L-Asp group, respectively). However, DAsp significantly declined rectal temperatures in broiler chicks $(\mathrm{F}(3,20)=5.81, P<0.005)$ as shown in Fig. 2. DAsp further showed a significant effect of time $(\mathrm{F}(3,2)=$ 25.09, $P<0.0001)$ and an interaction between the dose and time $(\mathrm{F}(6,40)=4.70, P<0.005)$ on declining body temperature, implying that the effect of D-Asp was more prominent with the progress of time and the low dose of the treatment caused more reduction in body temperature. Table 2 shows the changes in plasma metabolites due to the oral administration of D-Asp. A significant $(P<0.005)$ negative correlation was detected between the administered doses of DAsp and the plasma concentration of TG (143.4-4.1 X, $R^{2}$ $=0.295$ ). Plasma TG concentration significant decreased by $15 \mathrm{mmol} / \mathrm{kg}$ body weight D-Asp compared with the control

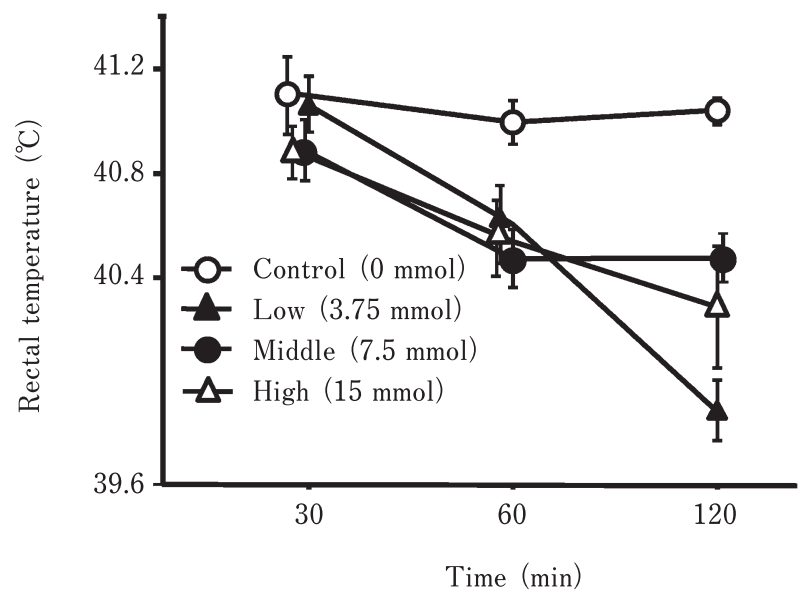

Fig. 2. Effect of orally D-Asp (3.75, 7.5 and $15.0 \mathrm{mmol} /$ kg) administration on rectal temperatures in chicks during $120 \mathrm{~min}$ of the experimental period (Experiment 2). The number of chicks used in each group ranged between 5-7. Values are means \pm S.E.M.

Table 1. Effects of oral administration of several doses of L-Asp on plasma metabolites in chicks (Experiment 1)

\begin{tabular}{|c|c|c|c|c|c|}
\hline \multirow{2}{*}{ Parameters } & \multicolumn{4}{|c|}{ L-Asp (mmol $/ \mathrm{kg})$} & \multirow{2}{*}{$\mathrm{R} 2$} \\
\hline & 0 & 3.75 & 7.5 & 15 & \\
\hline Glucose $(\mathrm{mg} / 100 \mathrm{~m} l)$ & $139 \pm 11$ & $127 \pm 5$ & $127 \pm 4$ & $125 \pm 3$ & 0.058 \\
\hline Total cholesterol $(\mathrm{mg} / 100 \mathrm{~m} l)$ & $192 \pm 8$ & $192 \pm 9$ & $181 \pm 11$ & $194 \pm 13$ & 0.000 \\
\hline Total protein $(\mathrm{g} / 100 \mathrm{~m} l)$ & $1.57 \pm 0.1$ & $1.54 \pm 0.1$ & $1.26 \pm 0.1$ & $1.54 \pm 0.2$ & 0.022 \\
\hline Triacylglycerol $(\mathrm{mg} / 100 \mathrm{~m} l)$ & $150 \pm 11$ & $157 \pm 23$ & $154 \pm 14$ & $140 \pm 14$ & 0.04 \\
\hline
\end{tabular}

Values are means \pm SEM. The number of samples used for analysis was 6-8. 
Table 2. Effects of oral administration of several doses of D-Asp on plasma metabolites in chicks (Experiment 2)

\begin{tabular}{|c|c|c|c|c|c|}
\hline \multirow{2}{*}{ Parameters } & \multicolumn{4}{|c|}{ D-Asp (mmol/kg) } & \multirow{2}{*}{$\mathrm{R} 2$} \\
\hline & 0 & 3.75 & 7.5 & 15 & \\
\hline Glucose $(\mathrm{mg} / 100 \mathrm{~m} /)$ & $124 \pm 4^{\mathrm{a}}$ & $131 \pm 2^{\mathrm{ab}}$ & $129 \pm 3^{\mathrm{ab}}$ & $140 \pm 3^{b}$ & 0.348 \\
\hline Total cholesterol $(\mathrm{mg} / 100 \mathrm{~m} l)$ & $204 \pm 5$ & $210 \pm 7$ & $232 \pm 22$ & $200 \pm 12$ & 0.0001 \\
\hline Total protein $(\mathrm{g} / 100 \mathrm{~m} l)$ & $1.67 \pm 0.1$ & $1.62 \pm 0.1$ & $1.63 \pm 0.1$ & $1.74 \pm 0.1$ & 0.023 \\
\hline Triacylglycerol $(\mathrm{mg} / 100 \mathrm{~m} l)$ & $147 \pm 15^{\mathrm{a}}$ & $107 \pm 15^{\mathrm{ab}}$ & $136 \pm 9^{a}$ & $75 \pm 8^{\mathrm{b}}$ & 0.295 \\
\hline
\end{tabular}

Means with different superscripts in the same row were significantly different at $P<0.05$.

Values are means \pm SEM. The number of samples used for analysis was 6-8.

$(\mathrm{F}(3,25)=6.51 P<0.005)$. On the other hand, a significant $(P<0.005)$ positive correlation was observed between the administered doses of D-Asp and the plasma concentration of glucose $\left(124.6+1.0 \mathrm{X}, R^{2}=0.348\right)$. Plasma glucose concentration was significant increased by $15 \mathrm{mmol} / \mathrm{kg}$ body weight D-Asp compared with the control $(\mathrm{F}(3,23)=5.00 P<0.01)$. The values of TP and TCHO showed no significant changes in any of the treated groups.

\section{Discussion}

We confirmed that oral administration of L-or D-Asp did not affect feed intake in broiler chicks. Our current findings on L-Asp concerning feed intake in broiler chicks is in accordance with other reports where it was shown that either peripheral or central administration of L-Asp did not influence feed intake in layer chicks (Maruyama et al., 1972; Bungo et al., 2002; Erwan et al., 2013a). However, the effect of D-Asp on feed intake differed with our recent study (Erwan et al., 2013a), since feed intake was significantly decreased when layer chicks were orally administrated with D-Asp. The reason for these discrepancies on feed intake behavior due to D-Asp is unknown. However, feed intake and growth rate is 1.5 to 2 -fold greater in broilers than in layers at 2 or 3 days old (Masic et al., 1974; Mahagna and Nir, 1996). It is well known that broiler chicks eat more food than layer-type chicks and then grow faster (NRC, 1994). Furuse et al. (2007) suggested that layers have higher levels of anorexigenic neuropeptides compared to broilers. Tachibana et al. (2001) revealed that agouti-related protein (AGRP) stimulated feed intake in layer-type chicks under an ad libitum feeding condition but not broiler chicks and suggested that the orexigenic effect of AGRP is different between the two breeds possibly due to the higher expression of its antagonist $\alpha$-melanocyte stimulating hormone in layers. Therefore, neuropeptide regulation of feed intake is different between broiler and layer type chicks. Although D-Asp dependent neuropeptide regulation for food intake is still unknown, we could hypothesize that D-Asp may influence the food intake regulatory circuitry in layers, but not broilers, due to having different food intake regulatory system in broilers and layers. Therefore, strain specific feeding regulation and variation in metabolic rate may cause the different responses for L- and D-Asp. Furthermore, it has been well documented that L- or D-Asp has a function as neurotransmitters to influence the central nervous system to regulate feed intake in rats. L-Asp is not only concentrated in nerve endings (Gundersen et al., 1991), but is also found localized and accumulated in common synaptic vesicles (Gundersen et al., 1998; Fleck et al., 2001). Thus, it could be further speculated that the administered dose of D-Asp might not have influenced physiological actions on neurocircuits in controlling feeding behavior in broiler chicks.

We also demonstrated here that L-Asp did not influence body temperature in broiler chicks. The result was accordance with the previous findings that oral administration of L-Asp did not decrease rectal temperature in rats (Koyuncuoğlu et al., 1982a; Koyuncuoğlu and Berkman, 1982) and in layer chicks (Erwan et al., 2014a). Interestingly, we have found that when L-Asp was chemically conjugated with lauric acid, a medium-chain fatty acid, then it enabled decreasing body temperature in layer chicks (Erwan et al., 2013b). Thus, it could be suggested that the chemical structure of L-Asp is not designed to influence body temperature but esterified L-Asp may have that potential.

Previous research findings revealed that the functions of different enantiomers are increasing (Gong et al., 2005; Yamane et al., 2009; Yoshida et al., 2015). It seems to be evident from the following reports that there were different responses due to the difference in enantiomers of L- or DAsp. Koyuncuoğlu and Berkman (1982) revealed that in rats, the concomitant oral administration of L-Asp seemed to antagonize the effect of D-Asp. The injection of D-Asp but not L-Asp released arginine vasopressin (AVP) in rats (Koyuncuoğlu et al., 1984). We have revealed the differences of L-Asp and D-Asp on stress response, feed intake and regulation of body temperature (Erwan et al., 2012, 2013a, 2013b, 2014). Further it was found that the mechanism of stress attenuating function of L- and D-Asp possibly occurs through different receptors (Erwan et al., 2012, 2014b). Koyuncuoğlu et al. (1982b) demonstrated that rectal temperature significantly decreased when rats received DAsp or D- plus L-Asp in a 1:1 ratio. Since the decreased body temperature by D-amino acids was antagonized by naloxone, an opioid antagonist (Koyuncuoğlu et al., 1982a), the decrease in rectal temperature might be caused by opioid 
system. Previous reports demonstrated that the injection of D-Asp increased AVP in rats (Koyuncuoğlu et al., 1984). The homologous nonapeptide AVP in birds is arginine vasotocin (AVT) (Acher et al., 1970). Similarly, to the function in mammal, AVT, a neurohypophyseal hormone in non-mammalian vertebrates, is involved in water balance in birds (Stallone and Braun, 1986). However, plasma levels of AVT increased in hypertonic solution and this response was further enhanced by naloxone injection as the doses increased (Saito et al., 1999). Furthermore, i.c.v. injection of AVT increased body temperature (Tachibana et al., 2004). These facts suggest that decreased body temperature induced by orally administered D-Asp could not be explained by increased AVT through the opioid system. Further investigations are needed to determine the relationships between DAsp and possible factors to regulate body temperature. This finding raised the possibility that D-Asp may be a useful hypothermic agent at HT not only for layer chicks but also for broiler chicks. Importantly, D-Asp did not reduce feed intake but caused to reduce rectal temperature in broiler chicks, which clearly indicate that the body temperature reduction by D-Asp may be due to its specific action on central or peripheral thermoregulatory mechanisms in broiler chicks. We assume that D-Asp dependent declining in rectal temperature may not be connected with metabolic function related regulation in body temperature since D-Asp reduced body temperature both in layer and broiler chicks. As the brain is the center of thermoregulation (Yahav, 2015), DAsp may have some function to control the thermal center in the brain. D-Asp may have some direct influence on this thermal center or indirect influence through peripheral sensory nervous system.

In Experiment 1, it was found that L-Asp did not influence any plasma metabolites studied. This finding confirmed our previous report in layer chicks (Erwan et al., 2014a). In addition, Tada et al. (2008) demonstrated that a subchronic oral administration of L-Asp with a dietary concentration of up to $5.0 \%$ had no influence on serum glucose in rats. Moreover, Delaney et al. (2008) and Karaman et al. (2011) also revealed that oral administration of L-Asp or N-acetylL-aspartic acid, an N-acetylated derivative of L-Asp, had no effect on TG, glucose, or TP. Thus, the present data corroborate those reported by others indicate that L-Asp or its derivative may not change the plasma metabolites in chicks especially in short term administration.

Consistent with previous research (Erwan et al., 2014a), plasma TG was found to be significantly decreased with the oral administration of D-Asp in the current study. Studies with rat (Koyuncuoglu et al., 1982b) and dogs (Shida et al., 1977) clearly showed the effect of decreasing plasma TG resulted hypothermia. It was further confirmed in this study that oral administration of D-Asp increased glucose (Table 2) as observed in layer chicks (Erwan et al., 2014a). A positive correlation between the dose of D-Asp and glucose suggest that D-Asp might have increased plasma glucose. These findings are consistent with earlier report that revealed that hypothermia resulted in increasing glucose (Shida et al.,
1977). In addition, Marley and Stephenson (1975) revealed that hypothermia was associated with increased blood glucose concentration in chicks. Therefore, the present results indicate that D-Asp dependent hypothermia may cause to increase energy demand in broiler chicks and thereby increase plasma glucose and decrease plasma TG.

In conclusion, oral administration of D-Asp, but not LAsp, could cause hypothermia in broiler chicks without affecting feed intake and altered some plasma metabolites namely, TG, and glucose. These results suggest the possibility of D-Asp as a potential hypothermic agent in chickens to mitigate heat-stress problems.

\section{Acknowledgments}

This work was supported by a Grant-in-Aid for Scientific Research (No.1107/R/2014 - to EE) from the State Islamic University of Sultan Syarif Kasim Riau, Indonesia.

\section{References}

Acher R, Chauvet J and Chauvet MT. Phylogeny of the neurohypophysial hormones. The avian active peptides. European Journal of Biochemistry, 17: 509-513. 1970.

Brake J, Balanave D and Dibner JJ. Optimum dietary arginine: lysine ratio for broiler chickens is altered during heat stress in association with changes in intestinal uptake and dietary sodium chloride. British Poultry Science, 39: 639-647. 1998.

Bungo $\mathrm{T}$, Yoshinaga $\mathrm{S}$ and Ueda $\mathrm{H}$. Intracerebroventricularly administered excitatory amino acids: effects on feeding behavior in chicks. Journal of Applied Animal Research, 22: 161-168. 2002.

Chowdhury VS, Tomonaga S, Nishimura S, Tabata S, Cockrem JF, Tsutsui $\mathrm{K}$ and Furuse M. Hypothalamic gonadotropin-inhibitory hormone precursor mRNA is increased during depressed food intake in heat-exposed chicks. Comparative Biochemistry and Physiology. Part A, Molecular \& Integrative Physiology, 162: 227-233. 2012.

Chowdhury VS, Tomonaga S, Ikegami T, Erwan E, Ito K, Cockrem JF and Furuse M. Oxidative damage and brain concentrations of free amino acid in chicks exposed to high ambient temperature. Comparative Biochemistry and Physiology. Part A, Molecular \& Integrative Physiology, 169: 70-76. 2014.

Chowdhury VS, Shigemura A, Erwan E, Ito K, Bahry MA, Tran V and Furuse M. Oral administration of L-citrulline, but not Larginine or L-ornithine, acts as a hypothermic agent in chicks. Journal of Poultry Science, 52: 331-335. 2015.

Dai SF, Gao F, Xu XL, Zhang WH, Song SX and Zhou GH. Effects of dietary glutamine and gamma-aminobutyric acid on meat colour, $\mathrm{pH}$, composition, and water-holding characteristic in broilers under cyclic heat stress. British Poultry Science, 53: 471-481. 2012.

Delaney B, Amanda Shen Z, Powley CR, Gannon S, Munley SA, Maxwell $\mathrm{C}$ and Barnett JF. Acute and repeated dose oral toxicity of N-acetyl-L-aspartic acid in Sprague-Dawley rats. Food and Chemical Toxicology, 46: 2023-2034. 2008.

Donkoh A. Ambient temperature: a factor affecting performance and physiological response of broiler chickens. International Journal of Biometeorology, 3: 259-265. 1989.

Errico F, Nisticò R, Palma G, Federici M, Affuso A, Brilli E, Topo E, Centonze D, Bernardi G, Bozzi Y, D’Aniello A, Di Lauro R, Mercuri NB and Usiello A. Increased levels of d-aspartate in 
the hippocampus enhance LTP but do not facilitate cognitive flexibility. Molecular and Cellular Neurosciences, 37: 236246. 2008.

Errico F, Napolitano F, Nisticò R, Centonze D and Usiello A. Daspartate: an atypical amino acid with neuromodulatory activity in mammals. Reviews in the Neurosciences, 20: 429-440. 2009.

Erwan E, Tomonaga S, Yoshida J, Nagasawa M, Ogino Y, Denbow DM and Furuse M. Central administration of L- and Daspartate attenuates stress behaviors by social isolation and CRF in neonatal chicks. Amino Acids, 43: 1969-1976. 2012.

Erwan E, Tomonaga S, Ohmori T, Mutaguchi Y, Ohshima T, Nagasawa $M$ and Furuse $M$. Oral administration of D-aspartate, but not of L-aspartate, reduces food intake in chicks. Journal of Poultry Science, 50: 164-171. 2013a.

Erwan E, Chowdhury VS, Ito K and Furuse M. Lauroyl-L-aspartate decreased food intake and body temperature in neonatal chicks. Pharmacology, Biochemistry, and Behavior, 113: 7-11. 2013b

Erwan E, Chowdhury VS, Nagasawa M, Goda R, Otsuka T, Yasuo S and Furuse M. Oral administration of D-aspartate, but not Laspartate, depresses rectal temperature and alters plasma metabolites in chicks. Life Sciences, 109: 65-71. 2014a.

Erwan E, Chowdhury VS, Nagasawa M, Goda R, Otsuka T, Yasuo S and Furuse M. Central injection of L- and D-aspartate attenuates isolation-induced stress behavior in chicks possibly through different mechanisms. European Journal of Pharmacology, 736: 138-142. 2014b.

Fleck MW, Barrionuevo G and Palmer AM. Synaptosomal and vesicular accumulation of L-glutamate, L-aspartate and Daspartate. Neurochemistry International, 39: 217-225. 2001.

Furuse M, Haruka Yamane H, Tomonaga S, Tsuneyoshi Y and Denbow D M. Neuropeptidergic Regulation of Food Intake in the Neonatal Chick: A Review. Journal of Poultry Science, 44: 349-356. 2007.

Gong XQ, Frandsen A, Lu WY, Wan Y, Zabek R, Pickering DS and Bai D. D-aspartate and NMDA, but not L-aspartate, block AMPA receptors in rat hippocampal neurons. British Journal Pharmacology, 145: 449-459. 2005.

Gundersen V, Ottersen OP and Storm-Mathisen J. Aspartate- and glutamate-like immunoreactivities in rat hippocampal slices: Depolarization-induced redistribution and effects of precursors. The European Journal of Neuroscience, 3: 1281-1299. 1991.

Gundersen V, Chaudhry FA, Bjaalie JG, Fonnum F, Ottersen OP and Storm-Mathisen J. Synaptic vesicular localization and exocytosis of L-aspartate in excitatory nerve terminals: a quantitative immunogold analysis in rat hippocampus. The Journal of Neuroscience, 18: 6059-6070. 1998.

Hamasu K, Shigemi K, Tsuneyoshi Y, Yamane H, Sato H, Denbow $\mathrm{DM}$ and Furuse $\mathrm{M}$. Intracerebroventricular injection of Lproline and D-proline induces sedative and hypnotic effects by different mechanisms under an acute stressful condition in chicks. Amino Acids, 38: 57-64. 2010.

Homma H. Biochemistry of D-aspartate in mammalian cells. Amino Acids, 32: 3-11. 2007.

Intergovernmental Panel on Climate Change (IPCC). Climate Change (2015) The Physical Science Basis. Contribution of Working Group I to the Fifth Assessment Report of the Intergovernmental Panel on Climate Change. http://www. climatechange 2014. org/images/uploads/WGIAR5_WGI-12Doc2b_FinalDraft All.pdf

Karaman S, Barnett J Jr, Sykes GP and Delaney B. Subchronic oral toxicity assessment of N-acetyl-L-aspartic acid in rats. Food and Chemical Toxicology, 1: 155-165. 2011.

Kera Y, Aoyama H, Watanabe N and Yamada R. Distribution of Daspartate oxidase and free D-glutamate and D-aspartate in chicken and pigeon tissues. Comparative Biochemistry and Physiology. Part B, Biochemistry \& Molecular Biology, 115: 121-126. 1996.

Koyuncuoğlu H and Berkman K. Effect of D- and/or L-aspartic acids on feeding, drinking, urine outflow and core temperature. Pharmacology, Biochemistry, and Behavior, 17: 1265-1269. 1982.

Koyuncuoğlu H, Berkman K, Wildmann J and Matthaei H. Antagonistic effect of L-aspartic acid on decrease in body weight, and food and fluid intake, and naloxone reversible rectal temperature depression caused by D-aspartic acid. Polish Journal of Pharmacology and Pharmacy, 34: 333-337. 1982a.

Koyuncuoğlu H, Wildmann J, Berkman K and Matthaei H. The effects of D- and/or L-aspartic acids on the total weight of body, the weights of certain organs, and their protein, triglyceride and glycogen content. Arzneimittel-Forschung, 32: 738-741. 1982b.

Koyuncuoğlu H, Berkman K, Hatipoğlu I and Sabuncu H. Vasopressin release by D-aspartic acid, morphine and prolyl-leucylglycinamide (PLG) in DI Brattleboro rats. Pharmacology, Biochemistry and Behavior, 20: 519-525. 1984.

Mahagna $\mathrm{M}$ and Nir I. Comparative development of digestive organs, intestinal disaccharidases and some blood metabolites in broiler and layer-type chicks after hatching. British Poultry Science, 37: 359-371. 1996.

Marley E and Stephenson JD. Effects of noradrenaline infused into the chick hypothalamus on thermoregulation below thermoneutrality. The Journal of physiology, 245: 289-303. 1975.

Maruyama K, Sunde ML and Harper AE. Effect of D-alanine and Daspartic acid on the chick. The Journal of Nutrition, 102: 1441-1451. 1972.

Masic B, Wood-Gush DGM and Duncan, IJH, Mccorquodale C and Savory CJA. Comparison of feeding behavior of young broiler and layer males. British Poultry Science, 15: 281-286. 1974.

Mendes AA, Watkins SE, England JA, Saleh EA, Waldroup AL and Waldroup PW. Influence of dietary lysine levels and arginine: lysine ratios on performance of broilers exposed to heat or cold stress during the period of three to six weeks of age. Poultry Science, 76: 472-481. 1997.

National Research Council, Nutrient Requirements of Poultry, 9th Revised Edition, The National Academy of Sciences, USA, 1994.

Neidle A and Dunlop DS. Developmental changes of free Daspartic acid in the chicken embryo and in the neonatal rat. Life Sciences, 46: 1517-1522. 1990.

Rossi, M, Kim MS, Morgan DGA, Small CJ, Edwards CMB, Sunter D, Abusnan S, Goldstone AP, Russell SH, Stanley SA, Smith DM, Yagaloff K, Ghatei MA and Bloom SR. A c-terminal fragment of agouti-related protein increases feeding and antagonizes the effect of alpha-melanocyte stimulating hormone in vivo. Endocrinology, 139: 4428-4431. 1998.

Saito N, Furuse M, Sasaki T, Arakawa K and Shimada K. Effects of naloxone on neurohypophyseal peptide release by hypertonic stimulation in chicks. General and Comparative Endocrinology, 115: 228-235. 1999.

Schell MJ, Cooper OB and Snyder SH. D-aspartate localizations imply neuronal and neuroendocrine roles. Proceedings of the National Academy of Sciences of the United States of America, 94: 2013-2018. 1997. 
Shida H, Morimoto M, Inokawa K and Tsugane J. The Role of the Liver in the Changes of acid-base balance and plasma lipids during Surface-induced deep hypothermia. Japanese Journal of Surgery, 7: 139-146. 1977.

SAS, Stat view, version 5 (1998) SAS Institute, Cary.

Spinelli P, Brown E, Ferrandino G, Branno, M, Montarolo PG, D'Aniello, Rastogi RK, D'Aniello B, Baccari GC, Fisher G and D'Aniello A. D-Aspartic acid in the nervous system of Aplysia Limacina: Possible role in neurotransmission. Journal of Cellular Physiology, 206: 672-681. 2006.

Stallone JN and Braun EJ. Regulation of plasma arginine vasotocin in conscious water-deprived domestic fowl. American Journal of Physiology, 250: R658-R64. 1986.

Tachibana T, Sugahara K, OhgushiA, Ando R, Kawakami S, Yoshimatsu $\mathrm{T}$ and Furuse M. Intracerebroventricular injection of agouti-related protein attenuates the anorexigenic effect of alpha-melanocyte stimulating hormone in neonatal chicks. Neuroscience Letters, 305: 131-134. 2001.

Tachibana T, Saito E-S, Saito S, Tomonaga S, Denbow DM and Furuse M. Comparison of brain arginine-vasotocin and corticotrophin-releasing factor for physiological responses in chicks. Neuroscience Letters, 360: 165-169. 2004.

Tada Y, Yano N, Takahashi H, Yuzawa K, Ando H, Kubo Y, Nagasawa A, Uehara S, Ogata A and Nakae D. Toxic effects of 1-aspartic acid at high dose levels on kidneys and salivary glands in Fischer 344 rats detected in a 90-day feeding study.
Food and Chemical Toxicology, 46: 2789-2795. 2008.

Topo E, Fisher G, Sorricelli A, Errico F, Usiello A and D'Aniello A. Thyroid hormones and D-aspartic acid, D-aspartate oxidase, Daspartate racemase, $\mathrm{H}_{2} \mathrm{O}_{2}$, and ROS in rats and mice. Chemistry \& Biodiversity, 7: 1467-1478. 2010.

Willemsen H, Swennen Q, Everaert N, Geraert PA, Mercier Y, Stinckens A, Decuypere E and Buyse J. Effects of dietary supplementation of methionine and its hydroxy analog DL-2hydroxy-4-methylthiobutanoic acid on growth performance, plasma hormone levels, and the redox status of broiler chickens exposed to high temperatures. Poultry Science, 90: 23112320. 2011.

Yahav S. Regulation of body temperature: strategies and mechanisms. In: Sturkie's Avian Physiology, 6th edn. Milwaukee, Wisconsin, pp 869-905. 2015.

Yamane H, Asechi M, Tsuneyoshi Y, Kurauchi I, Denbow DM and Furuse M. Intracerebroventricular injection of L-aspartic acid and L-asparagine induces sedative effects under an acute stressful condition in neonatal chicks. Animal Science Journal, 80: 286-290. 2009.

Yoshida J, Erwan E, Chowdhury VS, Ogino Y, Shigemura A, Denbow D and Furuse M. Comparison of centrally injected tryptophan-related substances inducing sedation in acute isolation stress-induced neonatal chicks. Pharmacology Biochemistry and Behavior, 129: 1-6. 2015. 